\title{
Physical - chemical interaction of injection waters with depleted gas formations
}

\author{
Dan-Paul Stefănescu, ${ }^{1, *}$ \\ ${ }^{1}$ Lucian Blaga University of Sibiu, Faculty of Engineering, Department of Industrial Engineering and \\ Management, Sibiu, Str. Emil Cioran nr.4
}

\begin{abstract}
In order that the physical - chemical interaction of the injection water with the porous-permeable or fissured medium of reservoirs do not lead to their degradation, it is necessary that the waters to meet a number of quality conditions. The treatment and conditioning of the injectable waters is imperative to do so due to the fact that their provenance is different, such as reservoir waters, wastewater resulting from various operations - petroleum operations, meteoric waters, etc. and, in particular, due to the very large volumes of injected water. Failure to follow the steps associated with the water treatment process inevitably leads to premature reduction of the injection wells receptivity. This aspect, as well as another, will be analysed in the context of this article. The injection of water in different geological formations, usually highly depleted, is a connected and defining one in the process of extraction of natural gas from reservoirs. The claim is based on the fact that the very large volumes of reservoir water taken from natural gas stream must be stored safely, otherwise their free discharge would create a real ecological catastrophe
\end{abstract}

\section{Introduction}

The treatment of increasing quantities of water to be injected into the earth's crust should be done at least for two reasons, one of which is related to the preservation of the integrity of the perforated area of the injection well, and the second reason is to maintain the receptivity as long as possible of the collector by non-clogging of its pores, collector rock being usually made up from a porous-permeable environment.

The reduction of the water flow section called the filtration section, occurs in this case, due to the mechanical impurities in the water, which enter the porous environment, on the one hand, and on the other hand due to the interaction of the water injected with the clay minerals, if they exist, resulting in their swelling. This phenomenon occurs against the background of the ion exchange that occurs between the injection waters and these clay minerals. It is desirable that after processing the injectable water they have a good washing capacity thus contributing to the placement in the pores of the collector of volumes with an order of very large size, volumes correlated with adequate flows.

* Corresponding author: dan.stefanescu@ulbsibiu.ro 


\section{Considerations regarding the processing of injectable water in geological formations}

The personal observations made on the site, over the years, regarding the volumetric percentages of the waters that make up a cubic meter of injectable water, are as follows: between (90-95)\% is the origin of the reservoir water from different productive horizons or different reservoirs, (3-5)\% surface water or reservoir water used in various petroleum operations, and the rest, by a few percent, from meteoric water.

Of these three categories of water, the reservoir water is the one that has a complex chemical composition to which mechanical impurities in the form of fine particles are added.

Table 1 shows the chemical content of the different reservoir waters extracted together with natural gas from a series of productive horizons belonging to a commercial natural gas field, located in the centre of the Transylvanian basin.

Table 1. Chemical content of reservoir water produced from a natural gas field located in the centre of Transylvania Basin

\begin{tabular}{|c|c|c|c|c|c|c|c|c|c|}
\hline Formation & Well & $\begin{array}{c}\text { Perforation } \\
\text { interval [m] }\end{array}$ & $\begin{array}{c}\text { Reser- } \\
\text { voir } \\
\text { rock }\end{array}$ & $\begin{array}{c}\mathbf{N a}^{+} \\
\mathbf{m g} / \mathbf{l}\end{array}$ & $\begin{array}{c}\mathbf{C a}^{\mathbf{2}} \\
\mathbf{m g} / \mathbf{l}\end{array}$ & $\begin{array}{c}\mathbf{M g}^{\mathbf{2}} \\
\mathbf{m g} / \mathbf{l}\end{array}$ & $\begin{array}{c}\mathbf{C l}^{-} \\
\mathbf{m g} / \mathbf{l}\end{array}$ & $\begin{array}{c}\mathbf{S O 4}^{\mathbf{2}} \\
\mathbf{m g} / \mathbf{l}\end{array}$ & $\begin{array}{c}\mathbf{H C O}^{\mathbf{3}} \\
\mathbf{m g} / \mathbf{l}\end{array}$ \\
\hline Sa VIb & 5 & $1982-1942$ & marl & 29200 & 3133 & 798 & 52576 & 18 & 518 \\
\hline Sa VII & 171 & $1986-1974$ & $\begin{array}{c}\text { sand+ } \\
\text { clay }\end{array}$ & 24339 & 3006 & 1520 & 46984 & 193 & 176 \\
\hline Sa VII & 19 & $1928-1894$ & marl & 38739 & 2710 & 1973 & 70033 & 136 & 262 \\
\hline Sa VII & 16 & $2030-2018$ & marl & 32393 & 3150 & 1401 & 59395 & 80 & 262 \\
\hline Sa VII & 16 & $2002-1967$ & $\begin{array}{c}\text { sand+ } \\
\text { clay }\end{array}$ & 34333 & 3360 & 1529 & 62941 & 367 & 256 \\
\hline Sa VIIIb & 8 & $2098-2058$ & marl & 27208 & 2324 & 981 & 48666 & 141 & 262 \\
\hline Bg IX+X & 197 & $2180-2504$ & marl & 9092 & 751 & 304 & 15957 & 200 & 225 \\
\hline $\begin{array}{c}\text { Bg VIII } \\
\text { b+XI+X }\end{array}$ & 190 & $2121-2480$ & $\begin{array}{c}\text { sand+ } \\
\text { clay }\end{array}$ & 16891 & 1002 & 608 & 29254 & 143 & 396 \\
\hline Bg X & 6 & $2482-2396$ & marl & 12780 & 404 & 122 & 20389 & 179 & 439 \\
\hline Bg XIa+b & 6 & $2588-2522$ & marl & 11019 & 606 & 61 & 17286 & 105 & 1506 \\
\hline Bg XI-XII & 131 & $2364-2580$ & marl & 13405 & 501 & 304 & 22162 & 164 & 274 \\
\hline Bn XII & 123 & $2564-2654$ & marl & 33400 & 1252 & 304 & 54076 & 192 & 658 \\
\hline $\begin{array}{l}\text { Bn XIII- } \\
\text { XIV }\end{array}$ & 110 & $2582-2747$ & marl & 15990 & 501 & 304 & 25708 & 158 & 1037 \\
\hline $\begin{array}{l}\text { Note! } \\
\text { Sa-Sarmatian, Bg-Buglovian, Bn-Badenian are the geological ages of the formations }\end{array}$ \\
\hline
\end{tabular}

The data in table 1 show that the mineralization of water differs, as expected, from one horizon to another, by the multitude of factors that have acted over time in this regard, such as: reduction of sulphates due to anaerobic bacteria, adsorption and the existence of the possibility of cation exchange in the presence of clay minerals, the dissolution of mineral salts through the migration of water as well as due to the type of contact and the speed of movement through the porous-permeable environment.

For information purposes, it is specified that after many analyses carried out over the years in the laboratories of physico-chemical analyses, on the samples of reservoir waters collected from the impurities separators of the wells, it was reached the identification, with sufficient accuracy, of the origin of the waters. In this way, it is possible to know whether 
the reservoir water comes from the same horizon from which natural gas is produced or from another layer, which implies the different treatment of these situations.

The temporary collection and storage of large volumes of wastewater is a cyclical process that directly influences the extraction of gas, which will be analysed in the last part of this article, in the context of monitoring the infrastructure for collecting - treating and injecting water into more or less energy depleted formations..

The great diversity of mineral waters from the mineralization point of view requires the treatment and conditioning of these waters in the sense of reducing those components that would inevitably lead to premature deterioration of the injection medium.

A first phase related to the purification of the reservoir water, which is insufficient, is that of removing the mechanical impurities by sedimenting them both in the wells separators and in the tanks for temporary collection and storage of waste water.

The second phase, which results in a good purification of the water due to the removal of the smallest fractions of mineral particles and chemical compounds of dimensions close to those of colloidal particles, is associated with chemical treatments. Following these treatments, the content of mechanical impurities should be within the limits (1-2) mg / liter, thus resulting in a period of years of use of the injection site. In time, only the finest colloidal particles will enter the pores of the collector, forming microparticles on the pores surfaces. [5,8]

The different chemical reagents used are meant, as by the phenomenon of colloidal coagulation, to drive through the floccules created mechanical impurities that will be deposited at the bottom of the reaction basins. In the absence of coagulants, the colloidal particles, in this case those that do not exceed 3-4 microns, do not deposit under the influence of the gravitational force they remain in dispersion and in a continuous brownian motion.

"To appear these colloidal particles, it is necessary to unite them into larger (aggregate) particles because their specific weight leads them to the sphere of incidence of the gravitational force" [1]. These aggregates that form in the liquid phase of the reservoir water, have the characteristics of a micelle being formed from the nucleus which together with the adsorption layer forms the granule. This together with the diffusion layer forms the micelle. (Figure 1).

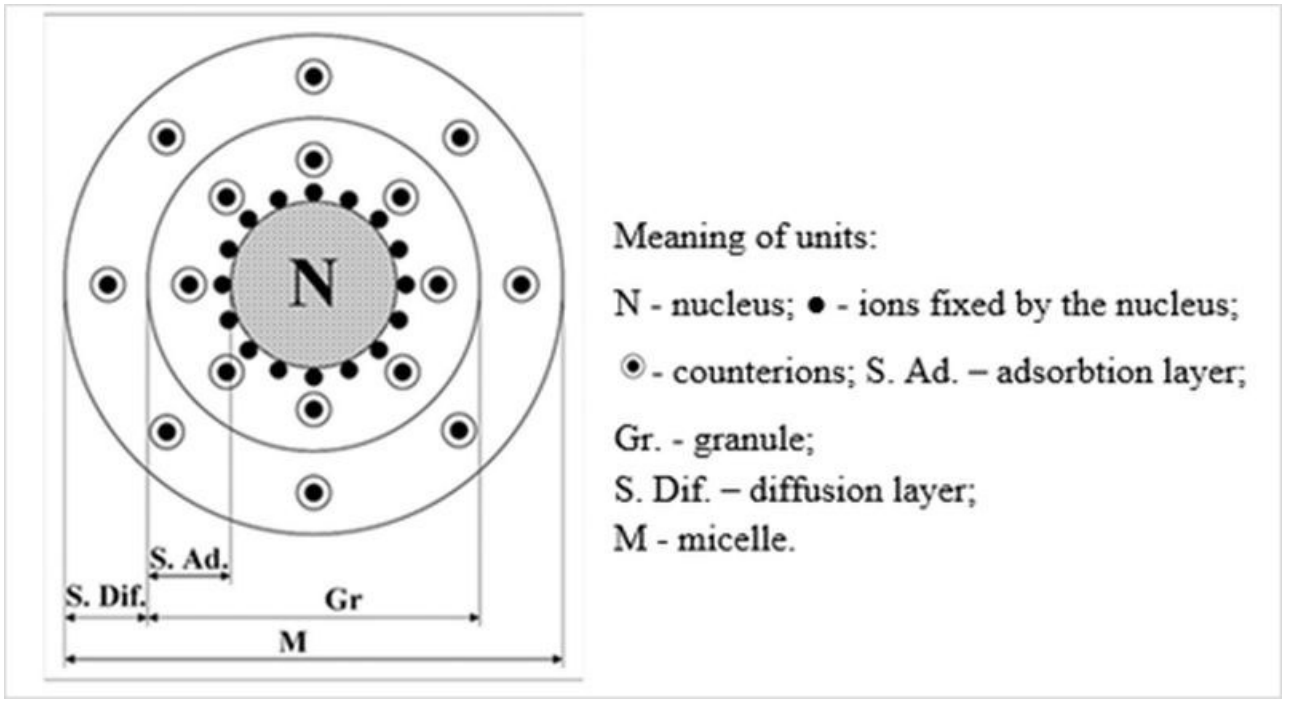

Fig. 1. The component of a micellar structure [1]. 
From Fig. 1 it is observed that around the nucleus there are strong ions connected to it as a result of the electrostatic forces. Around this arrangement are distributed ions which are called counterions. The last one are also in the diffusion layer (S. Dif.) and are under the influence of two opposite electrical charges; on the one hand they are held back by the electrical charges of the granule, and on the other hand they tend to disperse under the influence of the brownian movement.

The ions that are included at the boundary of the nucleus generate the so-called thermodynamic potential, and the counteraions in the adsorption layer contribute to the formation of the electrokinetic potential. Experimentally, it has been established that at an electrokinetic potential of less than $0.03 \mathrm{~V}$, the particles that collide with each other, as a result of the brownian motion, can form larger aggregates which, gravitationally, can accumulate at the bottom of the vessel.

The colloidal coagulation, mentioned earlier in this chapter, depends on the intensity of the brownian movement, which in turn increases with the rise of the water temperature to be treated.

In the practice of treating the reservoir waters in order to inject them into porouspermeable layers / formations are used coagulants, such as aluminum sulphate, which react with the calcium acid carbonate in the reservoir water, according to the reaction:

$$
\mathrm{Al}_{2}\left(\mathrm{SO}_{4}\right)_{3}+3 \mathrm{Ca}\left(\mathrm{HCO}_{3}\right)_{2}=3 \mathrm{CaSO}_{4}+2 \mathrm{Al}(\mathrm{OH})_{3}+6 \mathrm{CO}_{2}
$$

The resulting aluminum hydroxide, $\mathrm{Al}(\mathrm{OH})_{3}$, is deposited in the form of flakes, resulting in fine particles of mechanical impurities being deposited with it. Equally good results can be obtained by replacing aluminum sulphate with ferrous sulphate.

In order for the coagulation reaction to have a good yield, it is necessary to raise the $\mathrm{pH}$ of the water by alkalizing it. In this sense, the alkalization of water is achieved by the introduction of calcium hydroxide, which reacts with the resulting aluminum sulphate:

$$
\mathrm{Al}_{2}\left(\mathrm{SO}_{4}\right)_{3}+3 \mathrm{Ca}(\mathrm{OH})_{2}=2 \mathrm{Al}\left(\mathrm{OH}_{3}\right)+3 \mathrm{CaSO}_{4}
$$

Alkalization of the injectable water can also be achieved by replacing the calcium hydroxide with the sodium carbonate as per following reaction:

$$
\mathrm{Al}_{2}\left(\mathrm{SO}_{4}\right)_{3}+3 \mathrm{Na}_{2} \mathrm{CO}_{3}+3 \mathrm{H}_{2} \mathrm{O}=3 \mathrm{Na}_{2} \mathrm{SO}_{4}+2 \mathrm{Al}(\mathrm{OH})_{3}+3 \mathrm{CO}_{2}
$$

It is mentioned that the presence of petroleum products, for example condensate, in the flow of liquids trapped at the separator can create coagulation weights in order to slow down the process for which this product must be completely removed.

\section{Specific calculation methods for fluid flow through porous- permeable environment}

The transformation of the reservoir waters into injectable waters and injection into deep geological formations, is meant to preserve as much as possible the reception capacity of the porous - permeable environment. This quality, which is slowly changing over the time, must be preserved given the volume of the order of millions of cubic meters injected into these environments.

The huge volume of water is a mixture of reservoir waters from a large number of productive horizons / reservoirs, and their relocation is usually done in formations whose mineralogical composition is different from that of the origin of these waters. In these conditions, the interaction of the injection water with the porous - permeable medium is an inevitable one and further susceptible to a series of researches. 
The relatively long-term consequence of the interaction of the liquid phase with the solid one is found in the decrease of the injection rates and the increase of the pumping pressure, a sign that the receptivity of some wells is beginning to decrease. Direct interventions and within the reach of the operators consisting of the large penetration radius of the wellbore or acidization, statistically speaking, did not lead to an improvement of the receptivity of the well. Successful interventions must be viewed in the light of local improvement in the inflow receptivity of the area and by no means large areas of drainage that probably have not yet been seriously affected by the physical - chemical blockages.

The blockages in question are due to the presence almost without exception, in the collecting rocks, of the light-mineral minerals that can be in the proportion from 1 to $10 \%$, "being quite rarely found in a greater proportion, but also in a proportion smaller than $1 \%$ (clean sands) ". [2]

The clay minerals have a crystalline structure characterized by the presence in their network of silica, aluminum, $\mathrm{OH}$ groups and other alkaline and alkaline earth metals. This variety of constituent elements gives the clay minerals specific properties such as: small diameter of the particle and hence large specific surface area, high ionic exchange capacity and last but not least, high hydration capacity.[6,7]

The physico-chemical feature of these crystalline networks is their increased polarity which gives them intense activity in ion exchange with the polar fluids they come into contact with. This is the case of injection waters which, although chemically treated, are originally reservoir waters and thus have polarity.

It is unanimously recognized that the water to be injected into porous - permeable formations is an active solubilizer of many mineral salts, as well as of the organic molecules associated with the space in the earth's crust. The physical - chemical phenomenon mentioned above is accentuated by the existence of two defining parameters for the productive deposits / horizons / formations, namely the pressure and the temperature of the reservoir.

Returning to the data listed in the table 1 it is noted that a number of ions such as those of $\mathrm{Na}, \mathrm{Ca}, \mathrm{Cl}$, and even $\mathrm{Mg}$ have a major participation in the degree of mineralization of the reservoir waters, contributing significantly to their interaction with the crystalline networks of clay minerals.

The interaction between the solid phase, which is crystalline and polar with the injectable water, is made against the difference in concentration between the ions of the two phases, in the sense that the clay ions tend to diffuse in the aqueous solution. This ionic "migration" will also occur in the opposite direction from the aqueous solution to the crystalline network of clay minerals.

This ion exchange lasts until the ionic concentrations stabilize between the two phases, and the result is the swelling of the clay minerals and hence a number of drawbacks in both the hydrocarbon extraction process and the injection of the reservoir water. The swelling represents "the increase of the volume of the clay mineral or of the clay aggregates as a result of the retention of water by adsorption to the crystalline network and around the clay particle". [2]

In the national and international literature, a series of assessments are made both of the inter-crystalline swelling, which refers to the increase in volume as a result of the adsorption of water molecules on the surface of the particles and to the inter-crystalline swelling, that is, the expansion of the crystalline network by hydration.

The interaction of the injectable reservoir water with the porous - permeable formation where there is also a clay in which the sodium is a cation with a high dissociation degree, it easily passes into the diffusion layer, not neutralizing the clay particle. Thus, an expansion of the crystalline lattice occurs in a first step and a beginning of dispersion follows that in the second stage a total dispersion occurs. 
The phenomena associated with swelling and dispersion are related to each other and act in order to reduce the permeability of the layer / horizon where the injection of the reservoir water is made. Equally true is the fact that swelling and dispersion are practically irreversible phenomena.

The effects related to the decrease of the permeability of the layer are felt by the decrease in time of the receiving capacity in the wellbore zone and the propagation of this decrease towards the layer concomitant with a reduction of the injection flow rate. This aspect has direct repercussions on the functional parameters and the surface infrastructure that effectively performs water injection in the receiving formations.

The mathematical relation of the injection water flow carried in a porous - permeable environment is of the form:

$$
Q=\frac{2 \pi \cdot k_{a} \cdot h\left(p_{s}-p_{c}\right)}{\mu_{a} \cdot \ln \frac{r_{f}}{r_{s}}}
$$

where: $k_{a}, h,-$ efective permeability of the rock for water $(\mathrm{mD})$, respectively the net pay of water receptivity formation (m);

$\mu_{a}-$ dynamic viscosity of injection water (cP);

$r_{f}, r_{s}-$ the radius of the water advancement front, respectively, of the injection well,(m) ;

$p_{s^{-}}$the bottomhole pressure (bara), near the receiving layer, calculated by the relation:

$$
P_{s}=P_{p p}+\rho_{a} \cdot g \cdot H
$$

$P_{p p}$ - the pumping pressure (bara);

$\rho_{a}-$ density of the injection water $\left(\mathrm{kg} / \mathrm{m}^{3}\right)$;

$g$ - gravitational acceleration $\left(\mathrm{m} / \mathrm{s}^{2}\right)$;

$H$ - the height of the water column in the injection well (m);

$P_{c}-$ the back pressure applied to the water front (bara).

The relation (4) finds its applicability for the time intervals associated with small values of the back-pressure applied to the water advancement front. Accumulation over very long periods of very large amounts of water leads to increased back pressure on the advancing front due to the compression of the gas formation / horizon, on the one hand, and on the other hand due to the interaction of water with the porous - permeable environment. In these conditions the relation (4) loses its validity and the injected water flow will be estimated in the form [3]:

$$
Q=\frac{2 \pi \cdot h\left(p_{s}-p_{c}\right)}{\frac{\mu_{a}}{k_{a}} \ln \frac{r_{f}}{r_{s}}+\frac{\mu_{g}}{k_{g}} \ln \frac{r_{c}}{r_{f}}}
$$

where: - viscosity of natural gas, $(\mathrm{cP})$,

- efective permeability of the rock for gas, $(\mathrm{mD})$;

- the radius of boundary formation, (m);

- the same meaning as in relation (4). 


\section{The infrastructure required for the injection of the reservoir waters- results and discussion}

The process of water injection is carried out through a complex infrastructure composed of both surface technological installations and injection wells. The surface logistics includes the tank (approx. $200 \mathrm{~m}^{3}$ ) for temporary storage, coarse settling of mechanical impurities and separation of petroleum products (eg. condensate), the station for treatment and conditioning of the injectable water, fixed pumping groups and / or furniture, connecting pipes, annexes etc. The functionality of this technological assembly is ensured by the injection wells which are true channels of connection between the surface and the porous permeable environment.

It is rightly said that the optimal operation of the injection wells depends on the process of gas extraction because at this stage of exploitation of most commercial fields of natural gas in the Transylvanian Basin, and not only, the quantities of water drawn together with the gases are growing older. Major damage to the injection infrastructure, in particular to the injection wells may lead to the gas extraction process having technical and economic consequences not accepted by the profile companies.

In the figure 2 is the diagram of a water injection well [4].

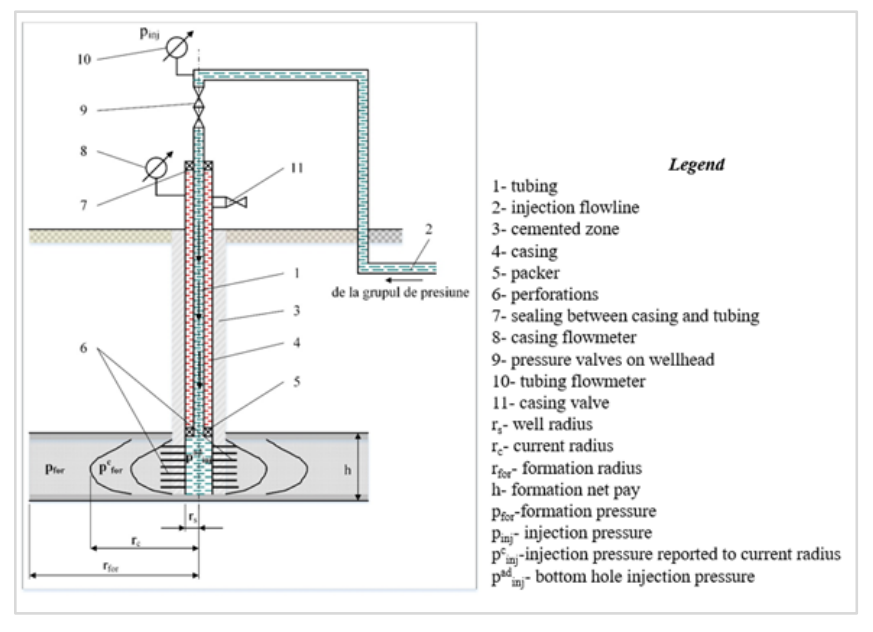

Fig. 2. The diagram of a water injection well

Due to the high values of injection pressure, between 70-140 bar, or even more, it is necessary to protect the operating casing of these wells and the groundwater. This is achievable by mounting in a well, at a predetermined depth, a layer separator called packer; see Fig. 2.

Normal operating parameters of an injection well are conditioned by the time constancy of the pressures and the injection rate which in turn is dependent of the effective permeability of the rock for the water phase, the viscosity of the water, the thickness of the layer, the effective radius of the injection well etc.

Towards the end of this article we present the practical results obtained from the operation of two injection wells, hereinafter referred to as well S1 and well S2. The spectacular results obtained, especially at the S2 well, illustrate the extent of the volumes of 
reservoir water collected and stored for injection into porous - permeable formations, volumes from only 165 gas producing wells in the central area of the Transylvanian Basin.

Well S1 was the subject of some primary investigations related to the beginning of the injection process and to the long-term injection of the reservoir waters .

Without going into a series of constructive details of the well, it is specified that its depth is at $1420 \mathrm{~m}$ (measured inside the operating casing) and the extraction pipes (tubing) are fixed at $848 \mathrm{~m}$. The receiving intervals are selectively distributed over a length of $44 \mathrm{~m}$ between the limits $928-864$.

Initiation of the injection flow at the well $\mathrm{S} 1$ began by performing a test of the receptivity of the layer and the adjacent pressure of $P_{s i}=150 \mathrm{bar}$, measured at the surface. Near the receiving layers the pressure was $P_{\text {inf }}^{a d}=242 \mathrm{bar}$, (see relation 3.2), higher by 35 bar compared to the fissured pressure of the rock, which according to the geological-technical data was estimated to be 207 bar. The fissures that probably were created could not be maintained without sand grains.

After injecting a first volume of water of approximately 20001 , the injection pressure stabilized to 140 bar. At this pressure and at a flow rate of $6.321 / \mathrm{s}$, the first batch of $20,000 \mathrm{l}$ of water with a specific weight $\gamma \mathrm{a}=1.09 \mathrm{Kgf} / \mathrm{dm}^{3}$ was introduced into the layer. Knowing that $\mu \mathrm{a}=0,9 \mathrm{mPa} \cdot \mathrm{s}$, estimated from graphs of the form $\mu \mathrm{a}=\mathrm{f}(\mathrm{T})$ for different salinities of the reservoir water, $\mathrm{rf}=0.27 \mathrm{~m}, \mathrm{rs}=10 \mathrm{~cm}$, formation pressure $=5 \mathrm{bar}$, could be determined at the moment respectively, the value of the effective rock permeability for the water phase. Applying the relation 3.1 resulted in $\mathrm{ka}=1.23 \mathrm{mD}$, a relatively small value for this parameter. However, in the S1 well, about $8100 \mathrm{~m} 3$ of reservoir water was injected from August 1992 to about 2000, the water coming from about 45 natural gas production wells.

The spectacular results continue to be obtained with the S2 injection well. The well became operational in 1993 and it is able to "take over" the water produced by 165 gas production wells.

Over the years, in the S2 well he has done a series of interventions works such as sand cleaning, reperforation and withdrawals to other layers with higher receptivity. At present, the top of cement is at $\mathrm{Hc}=990 \mathrm{~m}$, and the opening interval means $90 \mathrm{~m}$ and they are arranged on the range (770-938) $\mathrm{m}$, and the tubing shoe is fixed at $800 \mathrm{~m}$.

The values related to the volumes of water injected into the S2 probe are corroborated with injection pressures, values corresponding to the period 2009 - 2019 are absolutely revealing in this regard. (Table 2).

Table 2. Pressure values and volume of reservoir water injected in the period 2009-2019 (well S2)

\begin{tabular}{|c|c|c|c|c|c|c|c|c|c|c|c|c|}
\hline 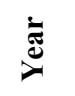 & ڤ્సે & 옥 & $\overline{\bar{N}}$ & 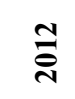 & $\stackrel{n}{\stackrel{7}{7}}$ & $\underset{\sim}{\stackrel{N}{N}}$ & $\stackrel{n}{\stackrel{2}{2}}$ & 록 & 록 & $\stackrel{\infty}{\stackrel{(}{N}}$ & 啇 & 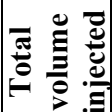 \\
\hline $\begin{array}{l}\text { Inj. } \\
\text { vol. } \\
{\left[\mathrm{km}^{3}\right]}\end{array}$ & 8 & 11 & 14 & 22 & 21 & 17 & 16 & 11 & 15 & 20 & 20 & 180 \\
\hline $\begin{array}{c}\text { Pres. } \\
\text { inj. } \\
\text { [bar] }\end{array}$ & $\begin{array}{c}70 \\
\div 72\end{array}$ & $\begin{array}{c}70 \\
\div 72\end{array}$ & $\begin{array}{c}70 \\
\div 72\end{array}$ & $\begin{array}{c}75 \\
\div 80\end{array}$ & $\begin{array}{c}75 \\
\div 85\end{array}$ & $\begin{array}{c}90 \\
\div 100\end{array}$ & $\begin{array}{c}120 \\
\div 130\end{array}$ & $\begin{array}{c}120 \\
\div 130\end{array}$ & $\begin{array}{c}120 \\
\div 130\end{array}$ & $\begin{array}{c}120 \\
\div 130\end{array}$ & $\begin{array}{c}120 \\
\div 130\end{array}$ & \\
\hline
\end{tabular}

The data from in table 2 show, as has been stated before, the size of the injection process of the reservoir waters in energy depleted formations. The total volume of water 
injected, of $180.691 \mathrm{~m}^{3}$ in 11 years, from only 165 wells is an impressive one. Simple calculations made around this volume, for example, show that 72.27 olympic swimming pools $(50 \times 25 \times 2)$ can be filled with water or the creation of a lake with a depth of $2 \mathrm{~m}$ with a surface of 4.51 hectares of lake.

\section{Conclusions}

1. The very large volumes of water that are injected in porous-permeable environments are subjected to a conditioning (treatment) process in order to significantly reduce the physico-chemical interaction of the waters with the prous-permeable environment of the former gas formations.

2. The different chemical reagents used have the purpose, through the phenomenon of colloidal coagulation, to drive through the floccules created the mechanical impurities that will be settled at the bottom of the reaction tanks.

3. Although the operating costs of the infrastructure for the treatment of injectable water are appreciable, they are fully justified and covered by the revenues resulting from the sale of gases thanks to the good functioning of the entire productive infrastructure of the respective commercial field. Failure to operate at the optimum parameters of the injection wells may inevitably lead to the gas extraction process being stopped.

\section{References}

1. A. Soare et al., Ingineria Zăcămintelor de Hidrocarburi, vol.2 (Editura Tehnică, Bucureşti, 1981)

2. I. Crețu et al., Ingineria Zăcămintelor de Hidrocarburi, vol.1 (Editura Tehnică, Bucureşti, 1981)

3. D-P. Ştefănescu, Practica Extracţiei Gazelor Naturale, vol. 2 (Editura Universităţii Lucian Blaga din Sibiu, 1998).

4. D-P. Ştefănescu, N. Strava, Revista Naţională de Gaze Naturale, 2 (1999).

5. I. Pârcălăbescu, Cercetări pentru elaborarea tehnologiei de preparare a apei de injecție adecvată zăcămintelor de hidrocarburi din Oligocenul de la Vâlcele, (Institutul de Petrol și Gaze Ploiești, 1978)

6. Gas Processors Suppliers Association, Engineering Data Book, SI Version, Vol.II, , Eleventh Edition, Section 18, Water Treating (Gas Processors Suppliers Association, 1988)

7. M.R. Beychok, Hydrocarbon Processing, 50, 12 (1972)

8. N.L. Nemerow, Theory and practice of industrial waste treatment (Addison-Wesley Publishing Co., Massachusetts, 1963) 